Tests of strength, resistance to fatigue and gastightness show the new joints to be fully as good as the old. The wiping technique is somewhat simpler and is well liked by jointers. The adoption of the new technique reduces the amount of tin the Bell System would ordinarily need for wiping solders by more than 60 per cent.

\section{Distribution of the Stars}

Dr. BART J. BoK, of Harvard, has made a report (S'ky and Telescope, August) on one of the first results of work by the so-called "star-counting circuit", which is an informal organization of several observa. tories in the United States and other countries. A search was made for comparatively unobscured regions along the Milky Way, and several fields have been discovered in which the light of the distant stars is only slightly dimmed by the absorption of interstellar matter. The most notable clear regions are in the constellations of Cepheus, Auriga, Monoceros, Carina and Centaurus. In the portion of the Milky Way which lies between the southern Coalsack and Cygnus, in which the star clouds of Sagittarius and Scutum fall, there are no regions which are rela. tively unobscured. Even for the brightest patches in this section the light of stars at 3,000 light years from the sun is dimmed by a whole magnitude. It appears that the stars of different spectral classes are not well mixed in our part of the Milky Way. It is remarkable that there is a rapid initial decrease in star densities for all classes in the direction of the galactic nucleus, and at 1,000 light-years from the sun the densities are very low. Higher densities are not found for the central regions until we reach three to five thousand light-years from the sun.

\section{Bibliography of Seismology}

THE present number of this important bibliography (13, No. 11, January to June, 1942), published at the Dominion Observatory at Ottawa by Ernest A. Hodgson with the assistance of four collaborators, maintains its previous high standard. There are seventy-seven items culled from world-wide sources covering topics from the strength of rock materials to world structure. Many items concern patents for geophysical prospecting such as item 5326, Williams, P. S., "Seismic Exploration Method", U.S. Patent 2,253,358, Aug. 19, 1941, and Beers, R. F., "Means for Analysing and Determining Geologic Strata", U.S. Patent $2,249,108$, July 15,1941 . Items from NATURE and Science News Letter are included. There has been some discussion recently concerning the geology of the beds of the oceans especially near shore-lines. This enhanced interest is mirrored in item 5313, Jones, O. T., "Continental Slopes and Shelves", Geographical Journal, 97, No. 2, 80-99 (London, Feb., 1941); and in item 5341, Shepard, Francis P., and Emery, K. O., "Submarine Topography off the California Coast", Geological Society of America Special Publications, No. 31, 171 pp., 4 charts, 18 pl., 42 fig. (New York, 1941). Reginald A. Daly made a contribution to NATURE concerning "Glaciation and Submarine Valleys" on Feb. 7, 1942 (pp. 156-60), item 5291.

\section{Earthquakes Registered in New Zealand}

DurING June 1942, eight large earthquakes were registered by the seismographs at Wellington, Auckland, Christchurch and Arapuni, according to Provisional Bulletin No. P-124 of the Dominion Observa- tory, Wellington. Two prominent shocks were on June 6 with epicentre east of the New Guinea region and focal depth about $100 \mathrm{~km}$., and on June 24 at Wairarapa. Thirty-one local earthquakes wera recorded during the period, including the Wairarapa shock mentioned above. This reached intensity 7 on the instrumental magnitude scale (New Zealand Bulletin P-104, p. 3) and was followed by nine principal aftershocks and about 418 minor shocks. Several of the aftershocks reached intensity $4 \frac{1}{2}$, and on June 25 an earthquake of intensity 4 was felt at Hokitika.

\section{Research in Industry}

IN connexion with the discussion of the relation of academic and industrial scientific research, Mr. Foster Sproxton has raised the question, in correspondence, of the position of the smaller industries which have no research associations. They may have problems arising in chemistry, physics, the various branches of engineering, or problems involving the biological sciences, outside the field of the regular scientific staffs employed at the factories. Guidance in the choice of an academic consultant would be of the greatest value in such industries. Mr. Sproxton believes that some kind of panel of academic scientific workers willing to assist in the solution of industrial problems would be of service, and suggests tentatively that such a function might form part of the activities of the Central Register.

\section{Dr. Gustav Retzius}

Dr. Gustav Magnus Retzius, a celebrated Swedish biologist, was born at Stockholm on October 17, 1842, the son of an eminent anatomist. $\mathrm{He}$ received his medical education at Uppsala and Stockholm, and qualified at Lund in 1871. Six years later he became 'extraordinary' professor of anatomy at the Caroline Institute at Stockholm. In 1889 he was appointed full professor, but resigned in the following year in order to devote himself entirely to scientific research, particularly in anatomy and anthropology, for which he travelled extensively in Europe and America. Most of his work was concerned with naked eye and microscopical anatomy, but he also made studies in embryology, anthropology, zoology and botany, so that he was a biologist in the fullest sense of the term. Betwean 1876 and 1906 he published six illustrated folios, the first of which was devoted to the anatomy of the nervous system and connective tissue, the second and third to anthropology, the fourth and fifth to the brain of man and monkeys and the sixth to the organ of hearing. His name has been given to parallel brown lines crossing the enamel-prisms of the teeth seen on cutting the enamel, and, with that of Key, to two foramina in the brain. He was awarded many prizes for his work, including the Montyon Prize of the Institut de France. He died on July 21, 1919.

Dr. WrLliam Bradley, lecturer in tinctorial chemistry and dyestuffs in the Manehester College of Technology, has joined the scientific staff of the British Drug Houses Ltd. His research work in organic chemistry includes the disclosure of the mechanism of the so-called Nierenstein reaction, the development of the theory of aromatic substitution by anionoid reagents, and the advancement of the chemistry of the anthocyanidins and of benzanthrone. 